\title{
Sociological Research on Russian Pupils' Financial Literacy as an Element of Project Management of Russian Students' Financial Education
}

\author{
Alexander Georgievich Tyurikov ${ }^{1 *}$, Yuriy Alekseevich Korablin ${ }^{1}$, Pavel Viktorovich Razov ${ }^{1}$, \\ Mikhail Viktorovich Kibakin ${ }^{1}$, and Semen Yurievich Bogatyrev ${ }^{2}$ \\ ${ }^{1}$ Financial University under the Government of the Russian Federation, Department of Sociology, \\ History and Philosophy, 125993, Moscow, Russia \\ ${ }^{2}$ Financial University under the Government of the Russian Federation, Department of Corporate \\ Finance and Corporate Governance, 125993, Moscow, Russia
}

\begin{abstract}
One of the differentiating characteristics and the main goal of this study has been to empirically study the financial literacy of modern Russian pupils and to determine their attitude to the problem of financial literacy in their everyday life. In order to solve the above goals, a set of sociological methods has been used, including a mass face-to-face survey of pupils from most regions of the country, a mass face-to-face online survey of students studying at the Financial University under the Government of the Russian Federation, in Moscow departments and departments of the regional branch network, an expert survey in regions of the Russian Federation, a content analysis of key electronic databases, e.g., the Russian State Library, the Library of Dissertations and Abstracts, the eLIBRARY.RU Scientific Electronic Library, a webometric analysis of more than 1,500 official websites of Russian regions on the problems under study, including the Usability and Visibility analysis. The authors have made some unique conclusions. Thus, more than $3 / 4$ of the modern youth understand the importance of financial literacy as an instrument to achieve their goals, and the goals demanded by the modern society. The main ones are to obtain education, to create a family, to achieve success in their career and professional growth, to establish their own business, etc. One important conclusion is as follows: the prospects for the use of deposits by today's pupils, mortgage lending, leasing, and participation in mutual investment funds (MIFs) have a number of fundamental regional differences. Moreover, these regional differences among pupils as potential investors may be demanded by modern commercial financial and credit organizations for preparing promising medium-term development plans for their regional branches.
\end{abstract}

\section{Introduction}

* Corresponding author: t-ag2013@yandex.ru 
The relevance of this study [1] is an attempt to empirically reveal the social contradiction of the modern Russian reality: on the one hand, this is constant quantitative and qualitative growth of innovative financial instruments in everyday life, and on the other hand, there is not always sufficient financial literacy of the population [2]. It means that people do not always manage to master the existing financial instruments to the proper degree and have to face the need to deal with new ones. The authors start revealing this problem through the example of pupils as potential users of various financial innovations [3]. This state of the society seriously complicates the ability of people to fully use real benefits of the civilization themselves, and, in addition, to provide their children with the financial education that is greatly required today. Therefore, there is a probability of violating the most important purpose of the social sphere of the society - expanded social reproduction of one of its most important components - the finances of the social sphere. It is quite obvious that financially literate behavior enables people to achieve success and well-being in the most efficient, "shortest" way, which, in its turn, is the foundation for the sustainable development of the country's economy, as a whole [4].

Thus, the main goal is to study the level of Russian pupils' financial literacy. In order to achieve it, certain tasks were set and solved: a mass face-to-face survey of pupils $(\mathrm{N}=731)$ from 66 regions of the country, a mass in-person online survey of students studying at the Financial University under the Government of the Russian Federation, in Moscow departments and departments of the regional branch network $(\mathrm{N}=4,413$ respondents), an expert survey in Russian regions $(\mathrm{N}=149)$, a content analysis of electronic databases of the Russian State Library, the Library of Dissertations and Abstracts, the eLIBRARY.RU Scientific Electronic Library, a webometric analysis of more than 1,500 official websites of Russian regions on the problems under study, including the Usability and Visibility analysis, were carried out.

This study has another scientific and practical direction that reflects the modern content of the pupils' financial culture [5]. There are the following problems within the authors' scientific and practical interests: the young people's awareness of the capabilities of modern financial instruments to achieve their personal goals, but at the same time the goals demanded by society, the ability to efficiently manage personal funds, the ability to understand the peculiarities of various financial products and services [6], the availability of relevant information on the situation in financial markets, Internet skills for financial education, and other issues under study.

\section{Methods}

The sociological study of the level of Russian pupils' financial literacy is only a small part of the larger study on the population's financial literacy carried out by the scientific and pedagogical staff of the Financial University under the Government of the Russian Federation in 2019 as part of the Strategy for Improving Financial Literacy in the Russian Federation for 2017 - 2023, approved by Decree of the Government of the Russian Federation No. 2039$\mathrm{r}$ dated September 25, 2017. The methods of mass and expert surveys, the content analysis on the theme under study, and the webmetric analysis (study of quantitative aspects of using information resources, structures, and technologies in relation to the Internet) of official websites dedicated to Russian regions on the issues under study were used. In particular, in the spring of 2019, a mass face-to-face online survey of the students studying at the Financial University under the Government of the Russian Federation, in Moscow departments and departments of the regional branch network $(\mathrm{N}=4,413$ respondents) was carried out. In September 2019, a mass face-to-face survey of pupils $(\mathrm{N}=731)$ who had arrived from sixtysix regions (some results of this survey are presented in this article) was carried out. In August - September 2019, there was an expert survey in the regions of the Russian Federation, with 
the possibility of comparing pilot and nonpilot regions $(\mathrm{N}=149)$. Besides, a content analysis of electronic databases of the Russian State Library, the Library of Dissertations and Abstracts, the Scientific Electronic Library eLIBRARY.RU, and a webmetric analysis of more than 1,500 official websites of Russian regions on the problems under study were carried out, including the Usability (usability of the website) and Visibility (visibility of the website) analysis.

The sources of information include the databases of works of the scientific community located on the largest Russian information and analytical portals in the field of science and electronic libraries: the Russian State Library [7], the DsLib.net Library of Dissertations and Abstracts [8], the disserCat Scientific Electronic Library of Dissertations and Abstracts [9], and the eLIBRARY.RU Scientific Electronic Library [10]. A content analysis was carried out according to the form containing the following semantic (key) units: financial literacy, financial behavior, and financially literate behavior, basics of financially literate behavior, types and strategies of financial behavior, financial culture, financial education, and financial competence.

\section{Results}

One of the distinguishing peculiarities of this study is the identification of the adequate attitude of young people to the problem of financial literacy in their lives [7-11]. The most expected answer - "the ability to manage personal funds efficiently" - was given by $80.6 \%$ of the responding pupils $(\mathrm{N}=731)$. Perhaps other figures turned out to be more interesting and to some extent unexpected $-76.2 \%$ considered "awareness of the capabilities of financial instruments to achieve goals" as one of the most important features of the financial literacy.

In addition, the thesis "the ability to understand the features of various financial products and services" as an indicator of the required knowledge, skills and abilities, i.e., real competencies, occupies the worthy place $(63.9 \%)$.

The self-assessment of own financial literacy by young people, taking into account the above empiricism, looks quite self-critical. Thus, about $2 / 3$ of the surveyed respondents consider themselves financially literate to one degree or another $(61.3 \%)$. It means that far from every young person considers himself or herself capable of using modern financial instruments to achieve well-being and success. However, understanding the importance of financial literacy as an instrument to achieve goals is perhaps even more important today. About one in ten found it difficult to answer the question, and a little more than a quarter said no to one degree or another $(28.7 \%$ ) about their own self-assessment of the financial literacy. It means that pupils realize the insufficiency of their potential on this issue.

Despite the fact that in their future lives, pupils plan to use financial instruments exactly as instruments to achieve their goals apparently demanded by the society, the classic bank deposit was in the first place $(52.2 \%$ ) among a number of financial instruments to be considered.

Modern young people use a wide range of information sources, trying not to neglect anything, perhaps except for advertising $(3.7 \%)$. The most popular sources include ratings of financial and credit organizations $(80.5 \%)$ and opinions of independent experts $(76.2 \%)$. This is a serious attitude to the issue. Further, with a large negative difference, there are recommendations from acquaintances and relatives $(33.5 \%)$, articles in mass media $(30.8$ $\%)$, television reports which they do not watch (12.8\%), and reviews on the Internet $(6.7 \%)$. It means that today even very young people like the older population are already cautious about Internet sources as reliable sources of serious information.

In order to study financial strategies of a modern pupil, a game experiment was carried out. The pupils were asked an open question in the style of Pushkin's tale about a goldfish: 
"Imagine the situation where you have personal free funds in the amount of RUB 150 thous. you do not need to give back. How could you manage, spend, invest, and use them in the financial market?" The pupils were allowed to answer the question in any way they wanted. As a rule, the respondents expressed several alternatives to their behavior, e.g., to use a part of the money for a deposit in a bank, to spend the other part on highly profitable stocks, and to spend the rest on traveling. Therefore, the pupils' responses were grouped into seven possible inceptive financial strategies. These strategies had a linear mode: investments in deposits $-40.5 \%$, investments in securities (as a rule, in stocks) $-19.3 \%$, investments in establishing own business $-13.4 \%$, spending money on personal needs $-13.3 \%$ (this included cars, traveling, expensive devices, etc.), difficulties in answering $-9.7 \%$, various expenses (parents, charity, housing conditions, etc.) $-8.2 \%$, and investments in own education - unfortunately, only $7.4 \%$.

The correlations of financial strategies by income clearly show a number of empirical regularities. Firstly, the young people from low-income families almost twice less often plan to deposit money $(25 \%-43.1 \%-39.4 \%)$. They are much more likely than others to invest in securities $(25 \%-21 \%-17.8 \%)$. They are almost twice likely to establish their own business $(20 \%-12.1 \%-14 \%)$.

Secondly, none $(0 \%)$ of the low-income respondents surveyed will spend the money obtained in the offered way on their personal needs, whereas, for example, for the people with an average income, this figure is as much as $14.5 \%$, and for those with a high income $-13.1 \%$.

Thirdly, the low-income respondents considerably more often have difficulties in answering $(20 \%-5.9 \%-11.9 \%)$. They do not believe in a goldfish even asked to dream on this. Apparently, they intend to make their fate on their own by taking efforts.

\section{Discussion}

Numerous modern studies on the financial literacy [12-18] often aim either at increasing the people's income, or at the ability to use certain financial instruments, or at researching some of the respondents' individual characteristics. Thus, German psychologists [19] note that “... the improvement of the financial literacy improves well-being, and higher education considerably enhances this effect for women..." Chinese researchers [20] pay attention to almost the same thing, but with their characteristic pragmatism: "The growing number of the references that pay the main attention to the developed world studies the effects of financial literacy (or its lack) on the well-being of households". The respondents' individual characteristics are quite peculiarly characterized by American economists [21]: “... a central component of the financial literacy is the ability to count and the emotional attitude to numbers (i.e., the mathematical anxiety). Thus, the driving force of forming the development of financial literacy is in the ability to understand numbers and have an emotional attitude to numbers..."

This study has another scientific and practical direction, reflecting the modern content of the pupils' financial culture. It is possible to mention such main expected results in the context of the pupils' attitude to the financial literacy: the ability to efficiently manage personal funds $(80.6 \%)$, the ability to understand the characteristics of various financial products and services as an indicator of the required knowledge, skills and abilities, i.e., real competencies $(63.9 \%)$.

In addition, it is necessary to pay attention to the pupils' final self-assessment. They believe that they can also fully manage the financial resources that are already at their disposal. However, earning, and, more than that, increasing money is not their strong point yet. Apparently, this is a fairly objective self-assessment of their capabilities - the first, rather reasonable step in mastering financial instruments to achieve goals. 
Some results of the study are rather interesting and not very expected. $76.5 \%$ of the respondents (more than $3 / 4$ of the sampled population !!!) indicated the awareness of the capabilities of financial instruments to achieve their goals. The goals pupils strive for - to obtain education, create a family, achieve success in a career and professional growth, establish their own business, etc. - are demanded by the modern society. Therefore, their achievement by using modern innovative financial instruments is an indicator of a rather high financial and economic maturity of the modern Russian society. The indicator "awareness of the capabilities of financial instruments to achieve goals" with the value of $3 / 4$ can be the basis for the project management of Russian students' financial education.

In addition, it is quite unexpected that the availability of such innovative financial instruments as an electronic wallet $(1.2 \%)$ or using a bank card $(3.0 \%)$ as an indicator of the financial literacy in terms of importance is within the statistical error of the study, which suggests, perhaps, that the availability of financial resources for a certain person does not indicate his or her financial literacy. It means that an electronic wallet and a bank card as perceived by a Russian pupil are just some (quite insignificant) of many indicators of the practical skills and the ability to use modern financial instruments.

It is very interesting that there is a difference in today's financial behavior and financial strategies for the future among pupils from megacities and other settlements with less than one million inhabitants. Mortgage plans are more typical for residents of smaller settlements. Classic deposits are the prerogative of the inhabitants of the megacity. Many other financial instruments, e.g., MIFs, leasing, and insurance investment are fundamentally more attractive for nonmegacities.

\section{Conclusion}

In general, the study goals have been achieved. The authors have determined interesting empirical patterns that put the definition of financial literacy in the necessary list of instruments for achieving goals: not only improving material well-being, but achieving goals in the broad sense of the word when tasks demanded by the society are solved.

It is noteworthy that such concepts as leasing or MIF have never been mentioned by the pupils from megacities, i.e., people from megacities and, conditionally, from provinces are slightly different, which in general implies a certain difference in the credit and financial policy in various regions of the Russian Federation. Moreover, modern commercial financial and credit organizations can take advantage of these differences to form promising mediumterm development plans for their regional branches.

\section{References}

1. J. Gathergood, J. Weber, J. Banking Finance 78, 58-83 (2017)

2. M. Muñoz-Murillo, P. B. Álvarez-Franco, D. A. Restrepo-Tobón, J. Behav. Experiment. Econ. 84 (2020)

3. Sh. Clark, M. Paul, R. Aryeetey, G. Marquis, J. Adolescence 68, 94-104 (2018)

4. M. Brown, C. Henchoz, Th. Spycher, J. Econ. Behav. Organ. 150, $62-85$ (2018)

5. L. Blue, P. Grootenboer, M. Brimble, Int. Rev. Econ. Educ. 16(Part A), 51-62 (2014)

6. G. Peng, F. Liu, W. Lu, K. Liao, L. Zhu, Finance Res. Letters 26, 56-62 (2018)

7. A.G. Tyurikov, D.A. Kunizheva, Power 28(1), 164-170 (2020)

8. Yu.A. Korablin, D.A. Kunizawa, K.Yu. Mishin, Legal Sci. Scien. Practical J. 11, 34-38 (2019) 
9. M.V. Kibakin, N.A. Orekhovskaya, A.G. Tyurikov, P.V. Razov, N.I. Kiseleva, Euras. J. Analyt. Chem. 12(7b), 1283-1289 (2017)

10. O.V. Kuznetsov, M.E. Rodionova, Yu.A. Korablin, Problems risk analys. 16(6), 90-100 (2019)

11. A.G. Tyurikov, M.V. Kibakin, Yu.A. Korablin, D.I. Markov, Legal Sci. Scien. Practical J. 12, 71-75 (2019)

12. I. B. Duissa, Factors affecting multidimensional financial literacy of College students in the Middle East, International review of the Economics of education (In press). Available at: https://doi.org/10.1016/j.iree.2019.100173

13. A. Anderson, F. Baker, D. T. Robinson, J. Financ. Econ. 126(2), 383-398 (2017)

14. S.Y. Bogatyrev, J. Rev. Global Econ. 7, 731-739 (2018)

15. D. Nie, E. Panfilova, V. Samusenkov, A. Mikhaylov, Sustainability 12(11), 4412 (2020)

16. X. Feng, B.Lu, X. Song, Sh. Ma, J. Empirical Finance 51, 119-137 (2019).

17. D.A. Brent, M. B. Ward, J. Environment. Econ. Manag. 90, 181-216 (2018)

18. Ch. Lin, Yu-J. Hsiao, Ch.-Yu. Yeh, Pacific-Basin Finance J. 43, 218-237 (2017)

19. Ch. E. Bannier, M. Schwarz, J. Econ. Psy. 67, 66-86 (2018)

20. G. Niu, Y. Zhou, H. Gan, Pacific-Basin Finance J. 59, 101262 (2020)

21. K. Segerlund, T. Lin, C. Strembeck, G. Tingchow, D. Westphal, J. Behav. Experiment. Econ. 74, 18-25 (2018) 